\title{
Heterologous expression of Oenococcus oeni malolactic enzyme in Lactobacillus plantarum for improved malolactic fermentation
}

\author{
Christina Schümann ${ }^{1,2}$, Herbert Michlmayr ${ }^{1}$, Reinhard Eder ${ }^{2}$, Andrés M del Hierro', Klaus D Kulbe', Geir Mathiesen ${ }^{3}$ \\ and Thu-Ha Nguyen ${ }^{1 *}$
}

\begin{abstract}
Lactobacillus plantarum is involved in a multitude of food related industrial fermentation processes including the malolactic fermentation (MLF) of wine. This work is the first report on a recombinant L. plantarum strain successfully conducting MLF. The malolactic enzyme (MLE) from Oenococcus oeni was cloned into the lactobacillal expression vector pSIP409 which is based on the sakacin P operon of Lactobacillus sakei and expressed in the host strain L. plantarum WCFS1. Both recombinant and wild-type L. plantarum strains were tested for MLF using a buffered malic acid solution in absence of glucose. Under the conditions with L-malic acid as the only energy source and in presence of $\mathrm{Mn}^{2+}$ and $\mathrm{NAD}^{+}$, the recombinant L. plantarum and the wild-type strain converted $85 \%$ $(2.5 \mathrm{~g} / \mathrm{l})$ and $51 \%(1.5 \mathrm{~g} / \mathrm{l})$, respectively, of L-malic acid in 3.5 days. Furthermore, the recombinant $L$. plantarum cells converted in a modified wine 15\% (0.4 g/l) of initial L-malic acid concentration in 2 days. In conclusion, recombinant $L$. plantarum cells expressing MLE accelerate the malolactic fermentation.
\end{abstract}

Keywords: L. plantarum, Oenococcus oeni, Malolactic fermentation, Malolactic enzyme

\section{Introduction}

Lactic acid bacteria (LAB) contribute to taste and texture of a wide range of fermented products and inhibit the growth of spoilage bacteria (Mozzi et al. 2010). This includes the application of LAB in winemaking to increase the stability of wines that undergo barrel or bottle-ageing. This process, the malolactic fermentation (MLF), normally occurs after the alcoholic fermentation (AF). Apart from the decarboxylation of L-malic into Llactic acid, MLF removes carbon sources of other microorganisms and bestows sensory changes to the wine (Bartowsky 2005). The genera mainly found during MLF are Lactobacillus, Leuconostoc, Pediococcus and Oenococcus. Due to its high tolerance to low $\mathrm{pH}$ and higher amounts of $\mathrm{SO}_{2}$ and ethanol, Oenococcos oeni is the primary species encountered during spontaneous MLF (Capozzi et al. 2010). Furthermore, O. oeni is the preferred organism for malolactic starter cultures, since the

\footnotetext{
* Correspondence: thu-ha.nguyen@boku.ac.at

${ }^{1}$ Food Biotechnology Lab, Department of Food Sciences and Technology,

University of Natural Resources and Life Sciences, Vienna, Austria

Full list of author information is available at the end of the article
}

presence of Lactobacillus sp. and Pediococcus sp. during MLF can lead to development of spoilage aroma and off-flavours (Moreno-Arribas and Polo 2005). However, also $O$. oeni is able to generate for example acetic acid, diacetyl (buttery flavour), mannitol (viscous, sweet) and mousy off-flavour (Bartowsky 2009). Additionally, O. oeni needs several weeks to degrade malic acid completely, and growth of LAB is often delayed or can even fail (Zhang and Lovitt 2005). Consequently, innovations are desirable to reduce malic acid in a faster and more efficient way.

The enzymatic nature of the MLF was first observed in a crude extract of L. plantarum (formerly called $L$. arabinosus) in 1948 (Korkes and Ochoa 1948). Initially, it was presumed that the decarboxylation of malic acid originates from an enzyme cascade, until Caspritz and Radler (Caspritz and Radler 1983) proofed that a single enzyme directly converts L-malic to L-lactic acid. This enzyme, usually referred to as the malolactic enzyme (MLE, not EC classified), is only active in the presence of catalytical concentrations of $\mathrm{NAD}^{+}$and $\mathrm{Mn}^{2+}$. To date the mechanism of the MLE is still unclear. 
The $\mathrm{pH}$ optimum of the MLE is around $\mathrm{pH}$ 6.0, therefore direct application to must or wine, where the $\mathrm{pH}$ is below 4.0, is not possible (Costantini et al. 2009). Several attempts to immobilize bacteria or even the MLE have been performed in order to improve the control and the yield of the MLF (Maicas 2001). The sequencing of the mle gene from Lactococcus lactis (Ansanay et al. 1993) followed by the description of the complete mle operon from O. oeni (Labarre et al. 1996) opened up new possibilities for genetic modifications aiming a more efficient MLF. Consequently, the MLE has been expressed in several organisms. An overview, including the conversion of L-malic acid per day by these strains, is shown in Table 1. One of the approaches is the use of Saccharomyces cerevisiae, allowing simultaneous alcoholic - and malolactic fermentation. Two accordingly modified yeast strains are already on the market in some countries (Sablayrolles 2009). However, this approach affects the flavour profile of the final wine resulting for example in less metabolised ethyl lactate and subsequent decreased mouthfeel (Husnik et al. 2007). Winemakers are dependent on the aroma given by LAB to create specific styles which is forced by consumer preferences for new product development (Lerm et al. 2010). For that reason, an alternative approach might be the application of genetically modified LAB, heterologously expressing the MLE, to perform MLF in a shorter time and to achieve new and possibly more attractive flavour variations.

Several inducible and controlled expressions systems have been developed for LAB. One of the best known systems is perhaps the nisin-controlled gene expression system (NICE) for L. lactis (Mierau and Kleerebezem 2005). However, L. lactis is not a wine related LAB. On

Table 1 Overview of recent work of MLE production in recombinant Escherichia coli, Lactobacillus plantarum, Saccharomyces cerevisiae and Schizosaccharomyces pombe.

\begin{tabular}{|c|c|c|c|c|}
\hline Source of mle & Expression host & $\begin{array}{l}\text { L-malic acid degradation (g/l } \\
\text { per day) }\end{array}$ & $\begin{array}{l}\text { Specific activity of crude } \\
\text { enzyme } \\
(\mathrm{U} / \mathrm{mg})\end{array}$ & References \\
\hline \multirow{2}{*}{$\begin{array}{l}\text { Lactobacillus } \\
\text { delbrueckii }\end{array}$} & Escherichia coli & 0.05 & ND & Williams et al. (1984) \\
\hline & $\begin{array}{l}\text { Saccharomyces } \\
\text { cerevisiae }\end{array}$ & 0.01 & ND & \\
\hline \multirow[t]{7}{*}{ Lactococcus lactis } & Escherichia coli & 0.23 & ND & Ansanay et al. (1993) \\
\hline & $\begin{array}{l}\text { Saccharomyces } \\
\text { cerevisiae }\end{array}$ & $0.39(\mathrm{pH} 3.0)$ & ND & \\
\hline & Escherichia coli & ND & 0.27 & Denayrolles et al. (1994) \\
\hline & $\begin{array}{l}\text { Saccharomyces } \\
\text { cerevisiae }\end{array}$ & $0.08(\mathrm{pH} 3.0)$ & 0.7 & Denayrolles et al. (1995) \\
\hline & $\begin{array}{l}\text { Saccharomyces } \\
\text { cerevisiae }\end{array}$ & $0.14(\mathrm{pH} 3.5)$ & 18 & Ansanay et al. (1996) \\
\hline & $\begin{array}{l}\text { Schizosaccharomyces } \\
\text { pombe }\end{array}$ & $1.50^{*},+(\mathrm{pH} 3.5)$ & ND & \\
\hline & $\begin{array}{l}\text { Saccharomyces } \\
\text { cerevisiae }\end{array}$ & $0.72^{+}(\mathrm{pH} 3.5)$ & ND & Bony et al. (1997) \\
\hline \multirow[t]{2}{*}{$\begin{array}{l}\text { Pediococcus } \\
\text { damnosus }\end{array}$} & $\begin{array}{l}\text { Saccharomyces } \\
\text { cerevisiae }\end{array}$ & $2.00^{+}(\mathrm{pH} \mathrm{3.3)}$ & ND & Bauer et al. (2005) \\
\hline & Escherichia coli & Not detectable & $0.13^{* *}$ & Labarre et al. (1996) \\
\hline \multirow[t]{5}{*}{ Oenococcus oeni } & $\begin{array}{l}\text { Saccharomyces } \\
\text { cerevisiae }\end{array}$ & 1,05 (pH 3.0) & 0.02 & Labarre et al. (1996) \\
\hline & $\begin{array}{l}\text { Saccharomyces } \\
\text { cerevisiae }\end{array}$ & $1.81^{+}(\mathrm{pH} \mathrm{3.5})$ & ND & Husnik et al. (2007) \\
\hline & $\begin{array}{l}\text { Saccharomyces } \\
\text { cerevisiae }\end{array}$ & 0.34 & ND & Liu and Li (2009) \\
\hline & Escherichia coli & ND & 14.9 & $\begin{array}{l}\text { Schümann (personal } \\
\text { communication)) }\end{array}$ \\
\hline & Lactobacillus plantarum & $5.0^{*},(\mathrm{pH} 4.0)$ & 22.1 & This work \\
\hline
\end{tabular}

Summary of available data on the consumption of L-malic acid ( $\mathrm{g} / \mathrm{l})$ per day from medium, $\mathrm{pH}$ is indicated in parenthesis. The specific activities of the crude extracts (CE) are presented in $\mu \mathrm{mol} / \mathrm{ml}$ per min and $\mathrm{mg}$ protein $(\mathrm{U} / \mathrm{mg})$. Schizosaccharomyces pombe ND, not determined

* conversion of malic acid similar to the control

**after ammonium sulfate precipitation

${ }^{+}$complete conversion of malic acid 
the other hand, L. plantarum occurs at different stages of wine production and performs MLF (Sáenz et al. 2009, Todorov and de Melo Franco 2010). An expression system based on the genes involved in sakacin P production has been developed for use in L. plantarum and is successfully applied for the production of different proteins (Sørvig et al. 2003, Sørvig et al. 2005, Halbmayr et al. 2008, Kolandaswamy et al. 2009). In the present study, we demonstrated the use of this expression system to clone and express the mle gene from $O$. oeni into L. plantarum and utilize the recombinant $L$. plantarum for malolactic fermentation.

\section{Materials and methods}

\section{Chemicals and enzymes}

Unless otherwise stated, all chemicals were obtained from Sigma-Aldrich (Steinheim, Germany) or Roth (Karlsruhe, Germany) and were of reagent grade. All restriction enzymes, T4 DNA ligase and Phusion HighFidelity PCR Master Mix (Finnzymes) were obtained from New England Biolabs (NEB, Frankfurt, Germany) while REDTaq ReadyMix PCR Reaction Mix was purchased from Sigma-Aldrich.

\section{Bacterial strains and growth conditions}

The organisms used in this study, O. oeni DSM 20252 and DSM 20255, purchased from the German Collection of Microorganisms and Cell Cultures (DSMZ, Braunschweig, Germany), E. coli OneShot TOP10 cells were from Invitrogen (Carlsbad, CA, USA). L. plantarum WCFS1, a single colony isolate of strain NCIMB8826 that was originally isolated from human saliva (Kleerebezem et al. 2003), is from the culture collection of the Norwegian University of Life Sciences, Ås, Norway. O. oeni $\left(25^{\circ} \mathrm{C}\right)$ and L. plantarum $\left(30^{\circ} \mathrm{C}\right)$ were grown in de ManRogosa-Sharp (MRS) broth (de Man et al. 1960) and when appropriate supplemented with erythromycin (5 $\mu \mathrm{g} / \mathrm{ml}$ ). E. coli was grown at $37^{\circ} \mathrm{C}$ in Luria-Bertani (LB) medium (Bertani 1951) with addition of $200 \mu \mathrm{g} / \mathrm{ml}$ erythromycin, when necessary. Agar plates were either made of MRS-agar (Merck, Darmstadt, Germany) or LB media including $15 \mathrm{~g} / \mathrm{l}$ agar.

\section{DNA isolation and sequence analysis}

Polymerase chain reaction (PCR) amplifications, restriction enzyme digestion, agarose gel electrophoresis, plasmid DNA isolation, and transformation in E. coli were performed as described previously (Sambrook and Russell 2001). The genes encoding the MLE from O. oeni DSM 20252 and 20255 were amplified from chromosomal DNA and the sequences are deposited in the GenBank database with the accession numbers GQ911572 and GQ924754, respectively.

\section{Construction of expression vector}

For heterologous expression of the MLE in L. plantarum the sakacin P based expression system (pSIP-vectors) (Sørvig et al. 2003) was used. The mle gene from O. оеni 20255 was amplified from genomic DNA using primers GATGATCTCGAGAAAAGACATCATCATCATCATCATGGTGGAGACTACAAGGATGACGATGACAAGATGACAGATCCAGTAAGTATTTTA and GAGCTCGAATTCTTAGTATTTCGGATCCCAC to introduce a $\mathrm{N}$-terminal tag consisting of an $\mathrm{His}_{6}$-tag (bold) and the enteropeptidase (enterokinase, EC 3.4.21.9) restriction site (italic). Subsequently, the PCR product and the vector pSIP409 were digested by restriction enzymes $\mathrm{XhoI}$ and EcoRI (underlined). Both fragments were ligated and the resulting plasmid was transformed into electrocompetent L. plantarum cells as described previously (Aukrust, and Blom 1992). Positive colony PCR amplified constructs were verified by sequencing, performed by a commercial provider, and the plasmid was named pSC9mle.

\section{Expression and purification of recombinant enzyme}

The recombinant $L$. plantarum harbouring pSC9mle was cultivated in 0.5 litre MRS broth, inoculated from a $10 \mathrm{ml}$ overnight culture. Thereafter, cells were grown for $8 \mathrm{~h}$ at $30^{\circ} \mathrm{C}$, before induction with $25 \mathrm{ng} / \mathrm{ml}$ peptide pheromone IP-673. After an induction time of $14 \mathrm{~h}$ at $25^{\circ} \mathrm{C}$ the cells were harvested by centrifugation $(4000 \times$ g, $10 \mathrm{~min}, 4^{\circ} \mathrm{C}$ ), washed three times with $0.9 \% \mathrm{NaCl}$ solution and resuspended in wash buffer (100 mM N-2hydroxyethylpiperazine-N'-2-ethanesulfonic acid (HEPES), $100 \mathrm{mM} \mathrm{KCl,} 20 \mathrm{mM}$ imidazole (AppliChem, Darmstadt, Germany), $\mathrm{pH}$ 6.0. The harvested cells were disrupted by using a French press (Aminco, Maryland, USA) and the cell debris was removed by ultracentrifugation $\left(100,000 \times \mathrm{g}, 30 \mathrm{~min}, 4^{\circ} \mathrm{C}\right)$. The MLE was purified using immobilized metal ion affinity chromatography (IMAC) column (15 ml - Bio-Rad Laboratories, Hercules, CA) that was equilibrated with wash buffer. The protein was eluted at a rate of $2 \mathrm{ml} /$ min with elution buffer containing $1 \mathrm{M}$ imidazole. Active fractions were pooled, desalted, concentrated and stored in $100 \mathrm{mM}$ HEPES, $0.5 \mathrm{mM} \mathrm{NAD}^{+}$and $0.1 \mathrm{mM}$ $\mathrm{Mn}^{2+}$ (pH 6.0).

\section{Activity assay and determination of protein and molecular mass}

Activity of the MLE was determined by measuring the decreasing amount of malic acid and increasing amount of lactic acid in the assay. The reaction mixture contained $100 \mathrm{mM}$ HEPES ( $\mathrm{pH}$ 6.0), $0.5 \mathrm{mM} \mathrm{NAD}^{+}, 0.1$ $\mathrm{mM} \mathrm{Mn}{ }^{2+}$ and $15 \mathrm{mM} \mathrm{L-malic} \mathrm{acid} \mathrm{(pH} \mathrm{6.0),} \mathrm{and} \mathrm{was}$ incubated at $45^{\circ} \mathrm{C}$ using an Eppendorf thermomixer. 
The reaction was started with the addition of $20 \mu \mathrm{l}$ enzyme and stopped after 5 min reaction time by heating at $70^{\circ} \mathrm{C}$ for $1 \mathrm{~min}$ to inactivate the enzyme.

The influence of $\mathrm{pH}$ and temperature on the activity of the recombinant malolactic enzyme was studied. HEPES buffer and L-malic acid solution were adjusted to $\mathrm{pH}$ between 5.0 and 7.0 with $\mathrm{KOH}$ and the analysis were performed as described above in the temperature range from $30^{\circ} \mathrm{C}$ to $50^{\circ} \mathrm{C}$.

Organic acids were analyzed by high performance liquid chromatography (HPLC) using a Dionex System (Summit and Chromeleon software, Sunnyvale, CA, USA) equipped with a Supelcogel H column $(25 \mathrm{~cm} \times$ $4.6 \mathrm{~mm})$ from Sigma-Aldrich $\left(40^{\circ} \mathrm{C}, 0.1 \% \mathrm{H}_{3} \mathrm{PO}_{4}, 0.2 \mathrm{ml}\right.$ $\mathrm{min}^{-1}$, injection volume: $20 \mu \mathrm{l}$ ) and a $210 \mathrm{~nm}$ UV detector. To confirm specificity to the L- form of malic and lactic acid, both acids were further quantified with enzymatic test kits from Roche, purchased from R-Biopharm (Darmstadt, Germany). The enzyme activity (U) is expressed as $\mu \mathrm{mol}$ of L-malic acid converted per minute at $45^{\circ} \mathrm{C}$.

The protein concentration was determined using the method of (Bradford 1976) with bovine serum albumin as standard. Protein samples were analyzed by sodium dodecyl sulfate polyacrylamide gel electrophoresis (SDSPAGE) (Laemmli 1970). Coomassie blue staining was used for the visualization of the protein bands.

\section{Influence of the $\mathrm{pH}$ in MRS medium on the heterologous MLE production}

The influence of $\mathrm{pH}$ on the plasmid stability and on the subsequent production of MLE was determined in MRS medium containing $5 \mu \mathrm{g} / \mathrm{ml}$ erythromycin. The recombinant strain was first grown in $5 \mathrm{ml}$ MRS medium at initial $\mathrm{pH}$ of 4.0, 5.0 and 6.0. The resulting cells were diluted into $100 \mathrm{ml}$ MRS medium in appropriate $\mathrm{pH}$ to final $\mathrm{OD}_{600}$ of 0.05 and further incubated until $\mathrm{OD}_{600}$ reached at least 0.2 before induction with $25 \mathrm{ng} / \mathrm{ml}$ peptide pheromone IP-673. After $24 \mathrm{~h}$, including $19 \mathrm{~h}$ of induction time at $25^{\circ} \mathrm{C}$, the induced cells were harvested (4.000 rpm, $10 \mathrm{~min}, 4^{\circ} \mathrm{C}$ ), washed twice with $0.9 \% \mathrm{NaCl}$ solution and resuspended in HEPES buffer ( $\mathrm{pH}$ 6.0). Thereafter, $0.5 \mathrm{ml}$ cell suspension was homogenized in Precellyse 24 (Bertin Technology, Montigny, France) in presence of $0.5 \mathrm{~g}$ glass beads $(0.5 \mathrm{~mm})$ and after centrifugation (16.000 rpm, $\left.10 \mathrm{~min}, 4^{\circ} \mathrm{C}\right)$ MLE activity in the cell free supernatant was determined.

The wild-type and the recombinant $L$. plantarum strains were also tested for their efficiency to decarboxylate $\mathrm{L}$-malic acid in a medium at $\mathrm{pH}$ 4.0. These strains were cultivated in $250 \mathrm{ml}$ MRS-medium including $5 \mathrm{~g} / \mathrm{l}$ $\mathrm{L}$-malic acid at $25^{\circ} \mathrm{C}$ for $24 \mathrm{~h}$ with initial $\mathrm{OD}_{600}$ of 0.1 and the recombinant strain was induced for $12 \mathrm{~h}$. Samples, taken at regular intervals, were assayed for cell density $\left(\mathrm{OD}_{600}\right)$ and quantity of L-malic acid. All experiments were performed in triplicate.

\section{Reduction of acidity in a malic acid solution}

Cells of the wild-type and the recombinant $L$. plantarum, harbouring pSC9mle, were used to compare their efficiency to convert L-malic acid. Both strains were cultivated anaerobically in $300 \mathrm{ml}$ MRS broth containing $5 \mathrm{~g} / \mathrm{l} \mathrm{L}$-malic acid. Additionally, the recombinant strain was also cultivated in the absence of L-malic acid. Cultures with initial cell density of $0.2\left(\mathrm{OD}_{600}\right)$ were grown at $30^{\circ} \mathrm{C}$ for $2 \mathrm{~h}$ before the recombinant strains were induced with $25 \mathrm{ng} / \mathrm{ml}$ peptide pheromone. Cells were harvested $\left(4,000 \mathrm{rpm}, 10 \mathrm{~min}, 20^{\circ} \mathrm{C}\right)$ after $6 \mathrm{~h}$ of induction at $25^{\circ} \mathrm{C}$, washed once with $500 \mathrm{ml} 0.9 \% \mathrm{NaCl}$ solution and resuspended in malolactic test solution (3 $\mathrm{g} / \mathrm{l} \mathrm{L-malic} \mathrm{acid,} \mathrm{pH} \mathrm{5.0).} \mathrm{Intracellular} \mathrm{MLE} \mathrm{activity} \mathrm{was}$ determined as described above. The cell suspensions were further diluted to a final $\mathrm{OD}_{600}$ of approximately 0.1 in $200 \mathrm{ml}$ malolactic test solution and $200 \mathrm{ml}$ malolactic test solution was supplemented with $0.1 \mathrm{mM}$ $\mathrm{NAD}^{+}$and $0.02 \mathrm{mM} \mathrm{Mn}^{2+}$. The malolactic test solution contained no antibiotics and inducing agent due to the use of pre-induced cells. These solutions were incubated at $25^{\circ} \mathrm{C}$ with regular sampling to measure the cell density $\left(\mathrm{OD}_{600}\right)$ and the content of malic and lactic acid by HPLC as described above. The according number of colony forming units (CFU) was determined using the most probable number (MPN) method. Therefore three serials of 10-fold dilutions were prepared in MRS medium, starting with $1 \mathrm{ml}$ sample of wild-type L. plantarum cells (from inoculated malolactic test solution) and incubated at $30^{\circ} \mathrm{C}$ for $48 \mathrm{~h}$.

\section{Decarboxylation of malic acid in modified wine}

The wild-type strain and the recombinant $L$. plantarum strain were also applied for conducting MLF in modified wine. The wine used, a Grüner Veltliner from vintage 2010, was adjusted to $\mathrm{pH} 5.0$ by deacidification (original total acid of $8 \mathrm{~g} / \mathrm{L}$ and $3 \mathrm{~g} / \mathrm{L}$ malic acid) with $\mathrm{CaCO}_{3}$. The deacidified wine had a final chemical analysis of $11.8 \mathrm{v} / \mathrm{v}$ alcohol, $24 \mathrm{mg} / \mathrm{l}$ free $\mathrm{SO}_{2}, 76 \mathrm{mg} / \mathrm{l}$ total $\mathrm{SO}_{2}$, $0.2 \mathrm{~g} / \mathrm{l}$ glucose, $0.4 \mathrm{~g} / \mathrm{l}$ fructose and $2.3 \mathrm{~g} / \mathrm{l} \mathrm{L}$-malic acid with a $\mathrm{pH}$ of 4.8 . This wine was further manipulated by addition of L-malic acid and adjustment to $\mathrm{pH} 5.0$ with 4.0 $\mathrm{M} \mathrm{KOH}$. To avoid possibilities of contamination the final wine was sterile filtered $(0.22 \mu \mathrm{m}$ filter membrane). Cells used for the experiment with modified wine, containing additionally $\mathrm{Mn}^{2+}$ and $\mathrm{NAD}^{+}$, were treated the same as described for the application in malolactic test solution.

The behaviour of cells, which are being able to adapt to wine, were investigated. Both strains were pre-cultured as described above with the following 
modifications: the pre-cultures were grown in $100 \mathrm{ml}$ MRS medium containing $5 \mathrm{~g} / \mathrm{l} \mathrm{L-malic} \mathrm{acid} \mathrm{over} \mathrm{night}$ and were used to inoculate $100 \mathrm{ml}$ MRS medium diluted with $25 \%$ modified wine ( $\mathrm{pH}$ 5.7). After $12 \mathrm{~h}$ incubation $1 \mathrm{ml}$ of these cultures, containing the cells that were pre-adapted to MRS medium with $25 \%$ modified wine, were inoculated to $100 \mathrm{ml}$ medium containing $50 \%$ modified wine ( $\mathrm{pH} 5.6$ ) and inducted when the cell density reached $\sim 0.2\left(\mathrm{OD}_{600}\right)$. The cells were harvested after $12 \mathrm{~h}$ induction. Each experiment was performed in triplicate in $250 \mathrm{ml}$ modified wine at $25^{\circ} \mathrm{C}$. Samples were taken regularly and tested spectrophotometrically for cell density $\left(\mathrm{OD}_{600}\right)$ and enzymatically for the content of L-malic acid as described above.

\section{Results}

Cloning, production and purification of the MLE in $L$. plantarum

The mle gene from O. oeni 20255 (accession No. GQ924754) was cloned into pSIP409 vector (Sørvig et al. 2005) to express the MLE in L. plantarum. The resulting plasmid pSC9mle encoded the following Nterminal leader sequence MVACSSRLEKRHHHHHHGGDYKDDDDKX including a $\mathrm{His}_{6}$ affinity tag in frame fused to the mle gene. Sequence analysis confirmed the mle gene encodes a protein of 568 amino acids with a calculated molecular mass of $62.3 \mathrm{kDa}$ and after purification a single band with a molecular mass of $\sim 60 \mathrm{kDa}$ appeared on the SDS-PAGE gel (Figure 1). The expression resulted in approximately $6.6 \mathrm{kU}$ of the recombinant MLE per litre fermentation broth with a specific activity of $22.1 \mathrm{U} / \mathrm{mg}$ (Table 2). After purification using profinity IMAC resins the specific activity increased approximately 10 folds to $217 \mathrm{U} /$ mg with a recovery of $53 \%$.

\section{Influence of $\mathrm{pH}$ and temperature on the purified recombinant enzyme}

The $\mathrm{pH}$ optimum of the purified enzyme was tested in HEPES buffer. The activity was highest between $\mathrm{pH} 5.5$ and 6.5, with maximum activity at $\mathrm{pH} 6.0$ (Figure 2A). The temperature optimum was determined to be $45^{\circ} \mathrm{C}$ when using HEPES buffer at pH 6.0 (Figure 2B). The enzyme activity decreased significantly above and below this temperature, and at $30^{\circ} \mathrm{C}$ the MLE retained about $72 \%$ of the activity compared to the activity at $45^{\circ} \mathrm{C}$ (Figure 2B).

\section{Effect of the $\mathrm{pH}$ in the growth medium on the production of MLE}

Heterologous expression of the MLE in L. plantarum was tested at $\mathrm{pH}$ 4.0, 5.0 and 6.0. As shown in Figure 3, the $\mathrm{OD}_{600}$ was significantly higher after $24 \mathrm{~h}$ of cultivation at $\mathrm{pH} 6.0$ and 5.0 compared to $\mathrm{pH}$ 4.0. The MLE

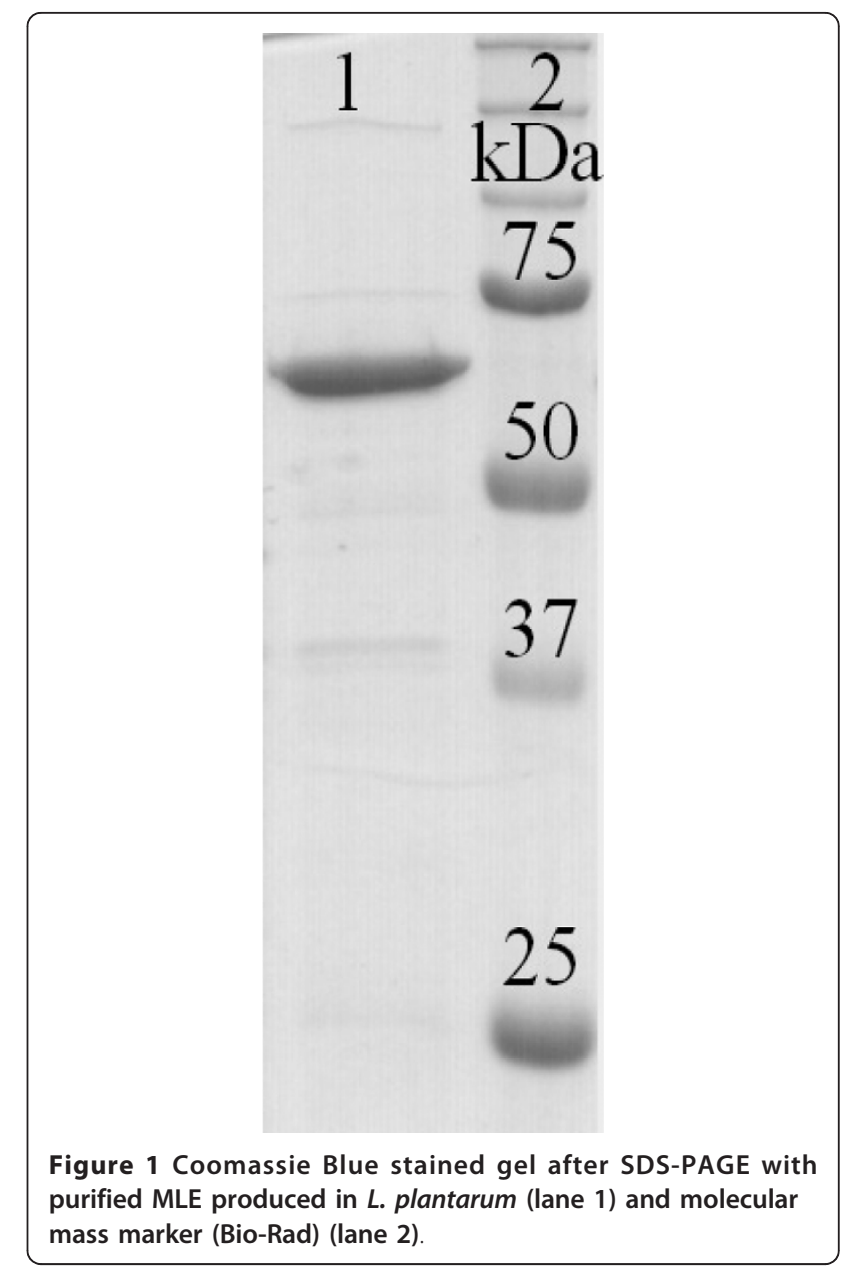

activity decreased significantly at $\mathrm{pH}$ below 6.0 in the medium, although similar protein contents of $13.4 \pm 0.5$ $\mathrm{mg} / \mathrm{ml}$ were determined after disruption of equivalent cell quantities. Interestingly, the activity of MLE obtained from the cultivation at $\mathrm{pH} 5.0$ was reduced more than $50 \%$ compared to $\mathrm{pH} 6.0$, while the $\mathrm{OD}_{600}$ was reduced approximately $25 \%$.

Analysis of the malolactic fermentation in MRS medium at pH 4.0 showed similar cell growth and decarboxylation of L-malic acid of the wild-type and induced recombinant L. plantarum strain (data not shown). Both wild-type and the recombinant strain converted $5 \mathrm{~g} / \mathrm{l} \mathrm{L}$ malic acid in $24 \mathrm{~h}$ and the final content of L-malic acid in the medium was found to be $0.025 \pm 0.001 \mathrm{~g} / \mathrm{l}$ (data not shown).

\section{Conversion of L-malic acid in malolactic test solution and modified wine}

To investigate the extent of L-malic acid conversion of the wild-type and the recombinant L. plantarum strain, both strains were incubated in a solution containing Lmalic acid as well as in a modified white wine. Since the 
Table 2 Purification of the recombinant MLE.

\begin{tabular}{lccccc}
\hline Purification step & Total activity (U) & $\begin{array}{c}\text { Total protein } \\
(\mathbf{m g})\end{array}$ & Specific activity (U/mg) & Purification (fold) & Recovery (\%) \\
\hline Crude extract & 3,289 & 148.7 & 22.1 & 1.0 & 100 \\
Affinity chromatography & 1,748 & 8.05 & 217 & 9.8 & 53 \\
\hline
\end{tabular}

The MLE was expressed in 0.5 litre and values are the mean of duplicate experiments

results shown above indicated that the initial $\mathrm{pH}$ affects the expression, cells were grown and induced in medium at $\mathrm{pH} 6.0$ before the malic acid conversion experiments were conducted.

The cells were harvested after $8 \mathrm{~h}$ and subsequently diluted to $\mathrm{OD}_{600}$ of $\sim 0.1\left(2.8 \times 10^{9} \mathrm{CFU} / \mathrm{ml}\right)$ for both strains to be used for L-malic acid conversion analysis. No detectable intracellular MLE activity was observed for the wild-type strain, on the other hand, $0.2 \mathrm{U} / \mathrm{ml}$ was determined for the recombinant cells used for the

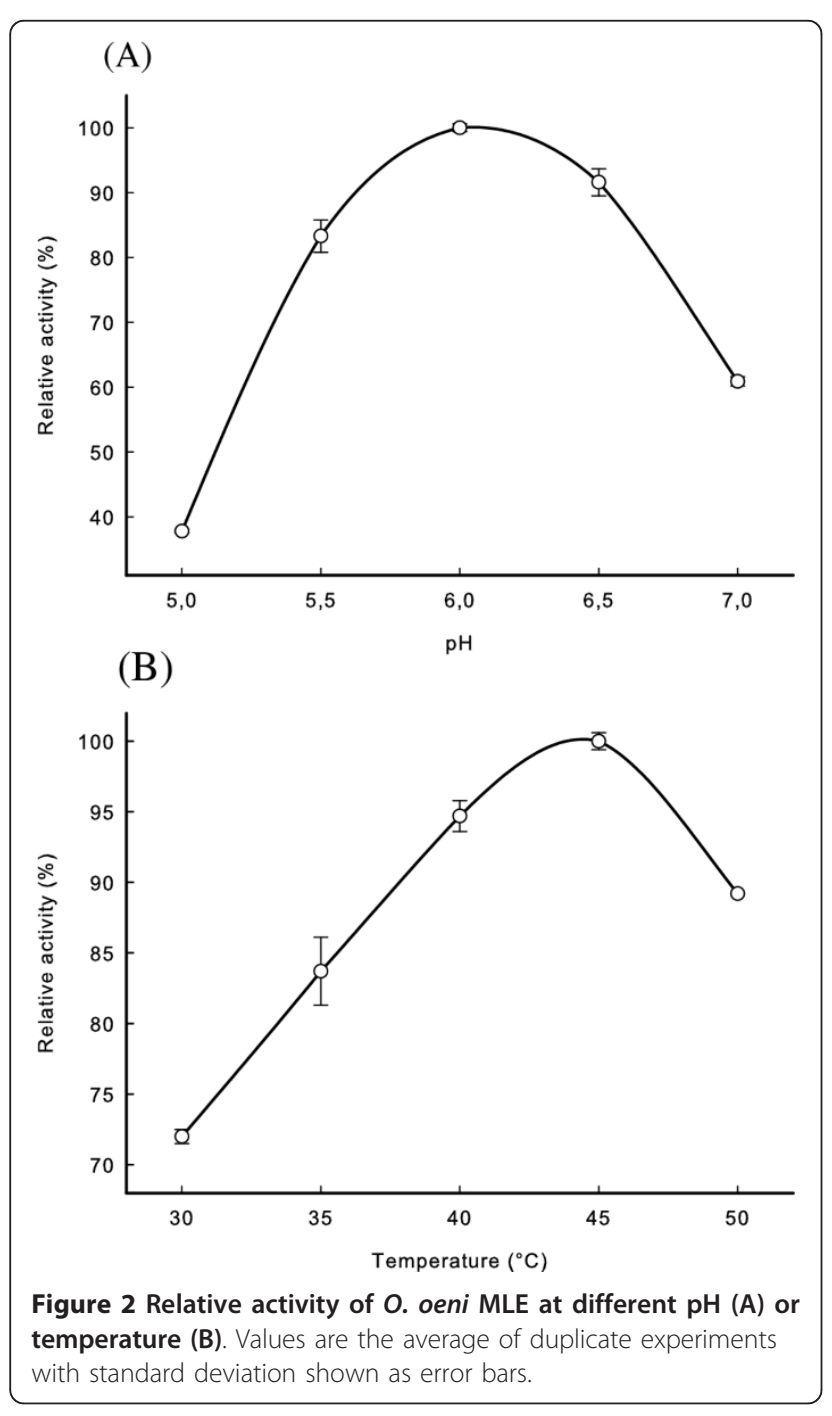

conversion of L-malic acid. The recombinant strain continuously converted L-malic acid reaching up to $85 \%$ $(2.5 \mathrm{~g} / \mathrm{l})$ in 3.5 days when the cofactors $\mathrm{Mn}^{2+}$ and $\mathrm{NAD}^{+}$ were present (Figure 4A). Figure 4B shows the conversion rates in relation to the cell density, indicating that the recombinant strain showed enhanced conversion, even in absence of the cofactors. In cultures with 0.02 $\mathrm{mM} \mathrm{Mn}^{2+}$ and $0.1 \mathrm{mM} \mathrm{NAD}^{+}$, L-malic acid conversion increased by $13 \%$ and $22 \%$ of the wild-type and the recombinant $L$. plantarum after $84 \mathrm{~h}$, respectively.

The conversion of L-malic acid was also tested using modified wine in a discontinuous fermentor. The application of the cells showed that the non-adapted wildtype L. plantarum hardly converted L-malic acid at all during the analysis period, while adapted cells continuously converted L-malic acid (Figure 5A). The non adapted recombinant cells converted $15 \%(0.4 \mathrm{~g} / \mathrm{l}) \mathrm{L}$ malic acid in 48 hours. The adapted recombinant cells converted even $25 \%$ of inital L-malic acid, although preadaption to wine resulting in 5 times less intracellular activity (data not shown). Furthermore, pre-adapted cells increased their density during incubation in modified wine. Taking the different cells densities into

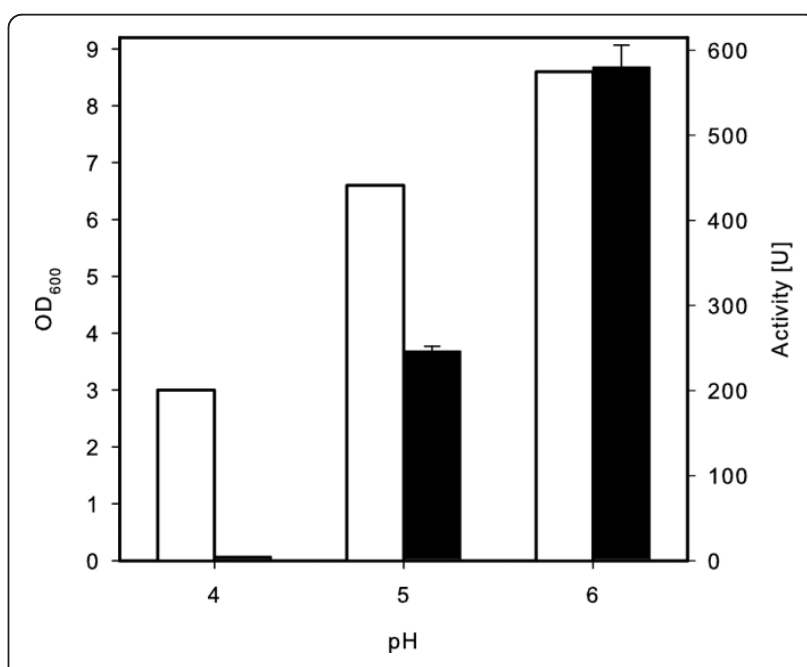

Figure 3 The optical cell densities $\left(\mathrm{OD}_{600}\right)$ (white bars) and malolactic activities (black bars) at different $\mathrm{pH}, 24 \mathrm{~h}$ after incubation in L. plantarum harbouring pSC9mle. The production of MLE was induced after $5 \mathrm{~h}$ of incubation. 


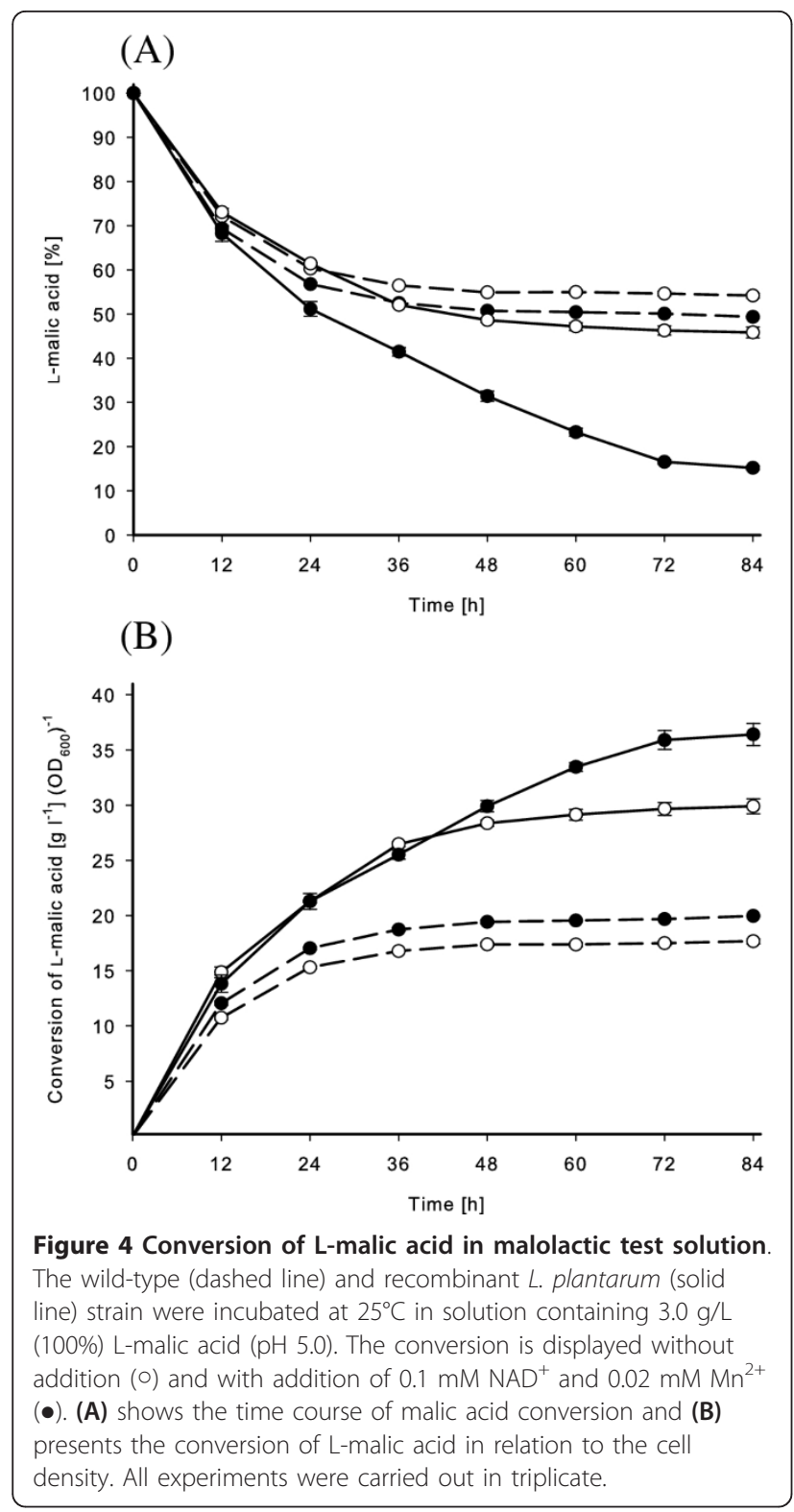

account, Figure 5B shows that non adapted recombinant cells showed highest conversion rate.

When using the recombinant L. plantarum strain, which was cultivated and induced in the absence of Lmalic acid, no decarboxylation was observed from the malolactic test solution (data not shown).

\section{Discussion}

At present, genetically modified organisms are already used in winemaking. Recombinant Saccharomyces strains conduct simultaneous alcoholic and malolactic fermentation, however, if the distinct aroma produced during MLF is desired, the use of LAB is necessary. Although $O$. oeni is the preferred microorganism to conduct MLF, recent research showed that $L$. plantarum

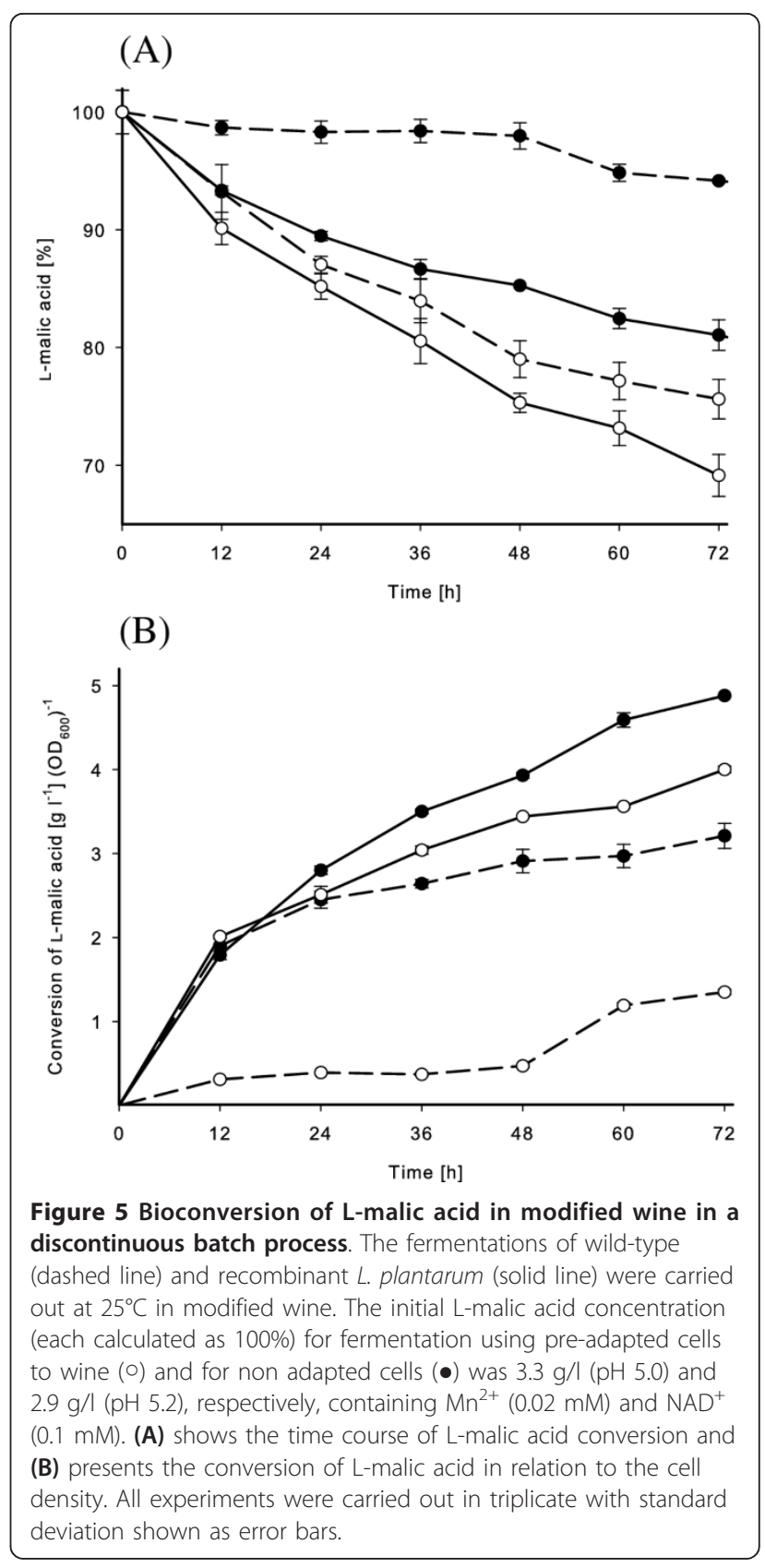

is a promising candidate to reduce L-malic acid in wine as well (Pozo-Bayon et al. 2005, du Toit et al. 2010). Not only that $L$. plantarum occurs naturally at different stages during wine making, it is also of interest as efficient antimicrobial agent to control spoilage microorganisms in winemaking (Navarro et al. 2008). Furthermore, wine related Lactobacillus species, including $L$. plantarum, are as efficient as $O$. oeni with excellent potential as starter cultures (du Toit et al. 2010). In this study we present a $L$. plantarum strain which produces recombinant MLE from $O$. oeni for enhanced MLF. The induced recombinant strain converted more 
L-malic acid and adapted better to wine condition than the wild-type L. plantarum.

This is the first report on the successful heterologous expression of MLE in a Lactobacillus spp. The L. plantarum WCFS1 which is a model strain in LAB research was selected for this study. The pSIP expression system (Sørvig et al. 2003) is well thoroughly tested in this strain and may produce level of the target protein to more than the half of total cellular proteins (Halbmayr et al. 2008). Previous attempts to conduct the MLF by recombinant Lactobacillus failed due to shuttle vector instability (Chagnaud et al. 1992). Although, the expression in L. plantarum strain (this study) is not as efficient as in $E$. coli, the enzyme activity obtained was 10 times higher compared to the native O. oeni strain (Schümann, personal communication). By comparing the specific activities of the crude MLE from $L$. plantarum with different expression hosts, the activity obtained in the present study is clearly the highest detected so far (Table 1). This illustrates the usefulness of the pSIP system for efficient production of malolactic enzyme in $L$. plantarum.

In the present study, we wanted to determine the ability of the recombinant L. plantarum strain to increase MLF compared to the wild-type strain. The application of MLF to wine necessitates the adaptation of microorganism to low $\mathrm{pH}$, therefore it is important to consider the influence of acidity on the used expression system. Our results showed that the expression of the recombinant strain was highest in a medium at $\mathrm{pH} 6.0$ and induction in the presence of even diluted wine decreased the expression level. Expression in a medium at $\mathrm{pH} 4.0$ led to undetectable activity and the application in MRS medium ( $\mathrm{pH} 4.0)$ resulted in similar conversion of the added L-malic acid ( $5 \mathrm{~g} / \mathrm{l})$ compared to the wild-type strain. This is probably at least partly due to loss of the expression plasmids from the L. plantarum at low $\mathrm{pH}$. It has previously been shown that the erythromycin gene which is used as selection for the plasmid has minimal activity at low $\mathrm{pH}$ (Lorian and Sabath 1970), and therefore the bacteria will dispose of the plasmid. To overcome this problem, L. plantarum cells were cultured and induced in a medium at $\mathrm{pH}$ 6.0, where cells showed highest malolactic activity, and then harvested and directly inoculated to L-malic acid containing solutions with $\mathrm{pH}$ 5.0-5.2. Using already induced cells as starter cultures enabled the application in the absence of the antibiotics and the inducing agent. The increased intracellular MLE activity probably enabled the recombinant strain to convert L-malic acid more efficiently than the wild-type strain and furthermore to survive longer under harsh conditions with no other substrate rather than L-malic acid (Figure 4B).
The role of $\mathrm{Mn}^{2+}$ and $\mathrm{NAD}^{+}$is not exactly clear due to similar rates of malic acid conversion during the first $36 \mathrm{~h}$ of reaction time (Figure 4A). It might be that the intracellular cofactors were metabolized to yield energy and subsequently to ensure survival of the cells.

The induced recombinant cells, pre-cultured without L-malic acid, were not able to convert L-malic acid in malolactic test solution, although significant intracellular MLE activity was detected. An explanation might be the lack of malate permease, responsible for the transport of malic acid into the cell, which is only expressed in presence of malic acid (Bandell et al. 1997).

The application of $L$. plantarum to modified wine showed that pre-adaption was necessary for the wildtype strain, while the recombinant strain was able to directly convert L-malic acid (Figure 5B). Interestingly, adapted recombinant cells, on the other hand, had a lower conversion rate per cells than non adapted cells. The reason might be either due to the inhibited expression during the cultivation in the presence of wine or the absence of $\mathrm{Mn}^{2+}$ and $\mathrm{NAD}^{+}$.

The advantage of over-expressing the MLE in L. plantarum for MLF was demonstrated in the present study. The pSIP expression system and the 'model' strain $L$. plantarum WCFS1 used in this study demonstrated that the expression of MLE in Lactobacillus is feasible and improved malolactic fermentation can be achieved. However, some optimizations have to be done for application in wine. The antibiotic resistance marker needs to be exchanged to a food-grade selection marker. This has recently been done with the pSIP vectors using alr gene as plasmid selection marker instead of the erythromycin gene. This system has successfully been applied for overexpression of a $\beta$-galactosidase (Nguyen et al. 2011).

In summary, this study showed the advantage of the recombinant $L$. plantarum, heterologously expressing the MLE, in terms of more efficient degradation of Lmalic acid and better adaption to wine conditions compared to the wild-type strain.

\section{Acknowledgements \\ We like to acknowledge the support by the Federal College and Research Institute for Viticulture and Pomology (HBLAuBA), Klosterneuburg, Austria. H. Michlmayr and A. M. del Hierro acknowledge support from the FWF Project P20246-B11. \\ Author details \\ ${ }^{1}$ Food Biotechnology Lab, Department of Food Sciences and Technology, University of Natural Resources and Life Sciences, Vienna, Austria ${ }^{2}$ Federal College and Research Institute for Viticulture and Pomology (HBLAuBA), Klosterneuburg, Austria ${ }^{3}$ Department of Chemistry, Biotechnology and Food Science, Norwegian University of Life Sciences, Ås, Norway}

Competing interests

The authors declare that they have no competing interests. 
Received: 17 February 2012 Accepted: 27 March 2012

Published: 27 March 2012

\section{References}

Ansanay V, Dequin S, Blondin B, Barre P (1993) Cloning, sequence and expression of the gene encoding the malolactic enzyme from Lactococcus lactis. FEBS Lett 332:74-80. doi:10.1016/0014-5793(93)80488-G.

Aukrust T, Blom H (1992) Transformation of Lactobacillus strains used in meat and vegetable fermentations. Food Res Int 25:253-261. doi:10.1016/09639969(92)90121-K.

Bandell M, Ansanay V, Rachidi N, Dequin S, Lolkema JS (1997) Membrane potential-generating malate (MleP) and citrate (CitP) transporters of lactic acid bacteria are homologous proteins: Substrate specificity of the 2hydroxycarboxylate transporter family. J Biol Chem 272:18140-18146. doi:10.1074/jbc.272.29.18140.

Bartowsky EJ (2005) Oenococcus oeni and malolactic fermentation - moving into the molecular arena. Aust J Grape Wine Res 11:174-187. doi:10.1111/j.17550238.2005.tb00286.x

Bartowsky EJ (2009) Bacterial spoilage of wine and approaches to minimize it. Lett Appl Microbiol 48:149-156. doi:10.1111/j.1472-765X.2008.02505.x.

Bauer R, Volschenk H, Dicks LMT (2005) Cloning and expression of the malolactic gene of Pediococcus damnosus NCFB1832 in Saccharomyces cerevisiae. J Biotech 118:353-362. doi:10.1016/j.jbiotec.2005.04.015.

Bertani G (1951) Studies on lysogenesis. I. The mode of phage liberation by lysogenic Escherichia coli. J Bacteriol 62:293-300

Bony M, Bidart F, Camarasa C, Ansanay V, Dulau L, Barre P, Dequin S (1997) Metabolic analysis of $S$. cerevisiae strains engineered for malolactic fermentation. FEBS Lett 410:452-456

Bradford MM (1976) A rapid and sensitive method for the quantitation of microgram quantities of protein utilizing the principle of protein-dye binding. Anal Biochem 72:248-254. doi:10.1016/0003-2697(76)90527-3.

Capozzi V, Russo R, Beneduce L, Weidmann S, Grieco F, Guzzo J, Spano G (2010) Technological properties of Oenococcus oeni strains isolated from typical southern Italian wines. Lett Appl Microbiol 50:327-334. doi:10.1111/j.1472$765 \times 2010.02795 \times$

Caspritz G, Radler F (1983) Malolactic enzyme of Lactobacillus plantarum. Purification, properties, and distribution among bacteria. J Biol Chem 258:4907-4910

Chagnaud P, Chan Kwo Chion CKN, Duran R, Naouri P, Arnaud A, Galzy P (1992) Construction of a new shuttle vector for Lactobacillus. Can J Microbiol 38:69-74. doi:10.1139/m92-011

Costantini A, Garcí-a-Moruno E, Moreno-Arribas MV Biochemical transformations produced by malolactic fermentation. In: Moreno-Arribas MV, Polo MC (ed) Wine Chemistry and Biochemistry. New York, Springer pp 27-57

de Man JD, Rogosa M, Sharpe ME (1960) A medium for the cultivation of lactobacilli. J Appl Bact 23:130-135. doi:10.1111/j.1365-2672.1960.tb00188.x.

Denayrolles M, Aigle M, Lonvaud-Funel A (1994) Cloning and sequence analysis of the gene encoding Lactococcus lactis malolactic enzyme: relationships with malic enzymes. FEMS Microbiol Lett 116:79-86. doi:10.1111/j.15746968.1994.tb06679.x

Denayrolles M, Aigle M, Lonvaud-Funel A (1995) Functional expression in Saccharomyces cerevisiae of the Lactococcus lactis mles gene encoding the malolactic enzyme. FEMS Microbiol Lett 125:37-43. doi:10.1111/j.15746968.1995.tb07332.x

du Toit M, Engelbrecht L, Lerm E, Krieger-Weber S (2010) Lactobacillus: the next generation of malolactic fermentation starter cultures - an overview. Food Bioprocess Tech 1-31

Halbmayr E, Mathiesen G, Nguyen TH, Maischberger T, Peterbauer CK, Eijsink VG, Haltrich D (2008) High-level expression of recombinant beta-galactosidases in Lactobacillus plantarum and Lactobacillus sakei using a Sakacin P-based expression system. J Agric Food Chem 56:4710-4719. doi:10.1021/jf073260+.

Husnik JI, Delaquis PJ, Cliff MA, van Vuuren HJJ (2007) Functional analyses of the malolactic wine yeast ML01. Am J Enol Vitic 58:42-52

Kleerebezem M, Boekhorst J, van Kranenburg R, Molenaar D, Kuipers $O$, Leer $R$ Tarchini R, Peters S, Sandbrink H, Fiers M, Stiekema W, Lankhorst R, Bron P, Hoffer S, Groot M, Kerkhoven R, de Vries M, Ursing B, de Vos W, Siezen R (2003) Complete genome sequence of Lactobacillus plantarum WCFS1. Proc Natl Acad Sci 100:1990-1995. doi:10.1073/pnas.0337704100.

Kolandaswamy A, George L, Sadasivam S (2009) Heterologous expression of oxalate decarboxylase in Lactobacillus plantarum NC8. Curr Microbiol 58:117-121. doi:10.1007/s00284-008-9286-6.
Korkes S, Ochoa S (1948) Adaptive conversion of malate to lactate and carbon dioxide by Lactobacillus arabinosus. J Biol Chem 176:463-464

Labarre C, Guzzo J, Cavin J, Divies C (1996) Cloning and characterization of the genes encoding the malolactic enzyme and the malate permease of Leuconostoc oenos. Appl Environ Microbiol 62:1274-1282

Laemmli U (1970) Cleavage of structural proteins during the assembly of the head of bacteriophage T4. Nature 227:680-685. doi:10.1038/227680a0.

Lerm E, Engelbrecht L, du Toit M (2010) Malolactic fermentation: the ABC's of MLF. S Afr J Enol Vitic 31:186-212

Liu Y, Li H (2009) Integrated expression of the Oenococcus oeni mleA Gene in Saccharomyces cerevisiae. Agric Sci China 8:821-827. doi:10.1016/S1671-2927 (08)60283-7.

Lorian V, Sabath LD (1970) Effect of pH on the activity of erythromycin against 500 isolates of gram-negative bacilli. Appl Microbiol 20:754-756

Maicas S (2001) The use of alternative technologies to develop malolactic fermentation in wine. Appl Microbiol Biotechnol 56:35-39. doi:10.1007/ s002530100662.

Mierau I, Kleerebezem M (2005) 10 years of the nisin-controlled gene expression system (NICE) in Lactococcus lactis. Appl Microbiol Biotechnol 68:705-717. doi:10.1007/s00253-005-0107-6.

Moreno-Arribas MV, Polo MC (2005) Winemaking biochemistry and microbiology: current knowledge and future trends. Crit Rev Food Sci Nutr 45:265-286. doi:10.1080/10408690490478118

Mozzi F, Raya PR, Vignolo GM (2010) Biotechnology of lactic acid bacteria: novel applications. Ames, lowa: Wiley-Blackwell

Navarro L, Rojo-Bezares B, Sáenz Y, Díez L, Zarazaga M, Ruiz-Larrea F, Torres C (2008) Comparative study of the pln locus of the quorum-sensing regulated bacteriocin-producing L. plantarum J51 strain. Int J Food Microbiol 128:390-394

Nguyen T, Mathiesen G, Fredriksen L, Kittl R, Nguyen TH, Eijsink VGH, Haltrich D, Peterbauer CK (2011) A food-grade system for inducible gene expression in Lactobacillus plantarum using an alanine racemase-encoding selection marker. J Agric Food Chem 59:5617-5624

Pozo-Bayon MA, G-Alegria E, Polo MC, Tenorio C, Martin-Alvarez PJ, Calvo de la Banda MT, Ruiz-Larrea F, Moreno-Arribas MV (2005) Wine volatile and amino acid composition after malolactic fermentation: effect of Oenococcus oeni and Lactobacillus plantarum starter cultures. J Agric Food Chem 53:8729-8735. doi:10.1021/jf050739y.

Sablayrolles JM (2009) Control of alcoholic fermentation in winemaking: Current situation and prospect. Food Res Int 42:418-424. doi:10.1016/j. foodres.2008.12.016

Sáenz Y, Rojo-Bezares B, Navarro L, Díez L, Somalo S, Zarazaga M, Ruiz-Larrea F, Torres C (2009) Genetic diversity of the p/n locus among oenological Lactobacillus plantarum strains. Int J Food Microbiol 134:176-183. doi:10.1016/j.jifoodmicro.2009.06.004.

Sambrook J, Russell DW (2001) Molecular cloning: a laboratory manual. Cold Spring Harbor, 3rd edn.N.Y: Cold Spring Harbor Laboratory Press

Sørvig E, Grönqvist S, Naterstad K, Mathiesen G, Eijsink VG, Axelsson L (2003) Construction of vectors for inducible gene expression in Lactobacillus sakei and L. plantarum. FEMS Microbiol Lett 229:119-126. doi:10.1016/S0378-1097 (03)00798-5.

Sørvig E, Mathiesen G, Naterstad K, Eijsink VG, Axelsson L (2005) High-level, inducible gene expression in Lactobacillus sakei and Lactobacillus plantarum using versatile expression vectors. Microbiology 151:2439-2449. doi:10.1099/ mic.0.28084-0.

Todorov SD, de Melo Franco BDG (2010) Lactobacillus plantarum: Characterization of the species and application in food production. Food Rev Int 26:205-229. doi:10.1080/87559129.2010.484113.

Williams SA, Hodges RA, Strike TL, Snow R, Kunkee RE (1984) Cloning the gene for the malolactic fermentation of wine from Lactobacillus delbrueckii in Escherichia coli and yeasts. Appl Environ Microbiol 47:288-293

Zhang DS, Lovitt RW (2005) Studies on growth and metabolism of Oenococcus oeni on sugars and sugar mixtures. J Appl Microbiol 99:565-572. doi:10.1111/ j.1365-2672.2005.02628.x

doi:10.1186/2191-0855-2-19

Cite this article as: Schümann et al:: Heterologous expression of Oenococcus oeni malolactic enzyme in Lactobacillus plantarum for improved malolactic fermentation. AMB Express 2012 2:19. 